\title{
BLDC Motor Driven Water Pump Fed by Solar Photovoltaic Array using Boost Converter
}

\author{
Kumar Harsh \\ Alumni, Dept. of Electrical Engineering \\ Vellore Institute of Technology, Chennai \\ Chennai, Tamil-Nadu, India
}

Rahul Kumar

Department of Avionics

Indian Institute of Space Science and Technology

Trivandrum, India

\author{
Kisalaya Pandey \\ Alumni, Dept. of Mechanical Engineering \\ Vellore Institute of Technology, Chennai \\ Chennai, Tamil-Nadu, India
}

Amit Kumar Jangir

Student, Dept. of Software Engineering

Vellore Institute of Technology, Chennai

Chennai, Tamil Nadu, India

\begin{abstract}
This paper presents the development of a simple, low cost, with high efficiency, more environmental friendly water pumping system. A DC-DC boost converter is used in between for power conditioning unit in the series of solar photovoltaic (SPV) fed to brushless DC motor (BLDC) driven water pump. The privileges of using the DC-DC Boost converter is that it controlled the starting inrush current and give the optimal output also. So, we don't need any external circuit for controlling the current, Also the speed of motor is controlled through the variable DC link voltage which removes the need of sensors

The framework is demonstrated, outlined and reported in matlab/Simulink and its different beginning, dynamics and steady state exhibitions are dissected under the practical operationg conditions, which show the responsible for water pumping.
\end{abstract}

Keywords-Solar;boost converter; BLDC motor; p\&o; mppt; control; open loop.

\section{INTRODUCTION}

High consumption of conventional fossil fuel which is going to get exhausted in next few years and the drastic reduction in cost of solar PV modules, power electronic devices and DSP's which is having a long life as well, motivated the researches and the industrialists well as the consumers towards its use.

One of the major reason why researchers are attracted towards SPV's is their everlasting generation technology and very low maintenance and running cost.

There are various applications of SPV's among all, the water pumping is becoming more attractive to the people. Since the motor and pump is coupled it should have less weight, easy voltage control, portable system, high efficiency, High permeability of the magnetic material, long life of the motor, high reliability, low noise production and less maintenance.By keeping all the above requirements, BLDC was preferred over Induction motor. The induction motor is getting replaced by BLDC in last few years due to lack of these features. Moreover the voltage source inverter(VSI), feeding the BLDC motor is operated with high frequency PWM pulses resulting in increased switching losses.
In this project the DC link voltage control methodology is used to control BLDC results no additional sensor requirement for speed control. Also in this work electronic computation is used to operate VSI, with the pulses of fundamental frequency to reduce the switching losses.

For the efficient use of solar energy, power optimization by maximum power point tracking(MPPT) is mandatory. MPPT performed between SPV's array and the VSI, the commonly used intermediate power conditioning unit is the non-isolated DC-DC converter such as buck, boost, buckboost, cuk etc. These non-isolated DC-DC converter have concluded that buck-boost converter is the best selection for SPV array system. From the various research, it is thoroughly justified that the buck-boost converter is also introduced for BLDC motor based on SPV array.

As compared to other topologies, such as cuk, sepia, zeta, esc converter the buck-boost converter operates with the best efficiency, but due to poor switch utilization and high stress on semiconductor becomes the main drawback of this device. On the other hand these topologies have higher value of reactive components which results in high cost, increased size and heavy weight. Therefore all these drawbacks of classical buck-boost converter or any other derived converters resulted in the rejection of these topologies for this work.

From the various reports, it is concluded that the classical buck and boost converter have a bounded region of mppt, hence they are unable to optimize the power under the variable loads. So, SPV array is slected such tgar its point of maximum power always occurs within the bounded MPP region of the desired converter, so that the power will always optimized despite of the variation in solar irradiance and loading condition. Also the solar PV output is less, so it need to be boosted up. Therefore boost converter is selected for this work.

The ideal choice of SPV's array and legitimate control of boost converter through MPPT calculation additionally gurantee the restricted starting in rush current of the BLDC motor with no extra control or circuitary offering the simplicity, compatibleness and cost effectiveness. 
The proposed water pumping framework is intend to work effectiveoly even at $20 \%$ solar irradiance of the standard case.

The framework is demonstrated, outlined and reported in matlab/Simulink and its different beginning, dynamics and steady state exhibitions are dissected under the practical operationg conditions, which show the responsible for water pumping.

\section{PROPOSED FRAMEWORK}

Fig. 1 demonstrates the arrangement of the proposed SPV cluster based boost converter encouraged BLDC motor driven water pump. From left to right, the proposed framework comprises of a SPV cluster, a boost converter, a VSI, a BLDC motor coupled to a water pump. The Perturb and Observe $(\boldsymbol{P} \& \boldsymbol{O})$ method MPPT strategy is utilized for control advancement of the SPV exhibit. The beat generator creates exchanging signals for the boost converter by looking at the ideal estimation of obligation cycle, created by the MPPT calculation, with the high recurrence saw-tooth bearer flag. The high exchanging recurrence comes about in a low estimation of the parts. The Hall-impact sensors mounted on the BLDC motor creates three Hall signals following the rotor position, which are additionally changed over, by electronic compensation, into six major recurrence changing heartbeats to work the VSI. The outline and control of proposed framework are expounded in following segments.

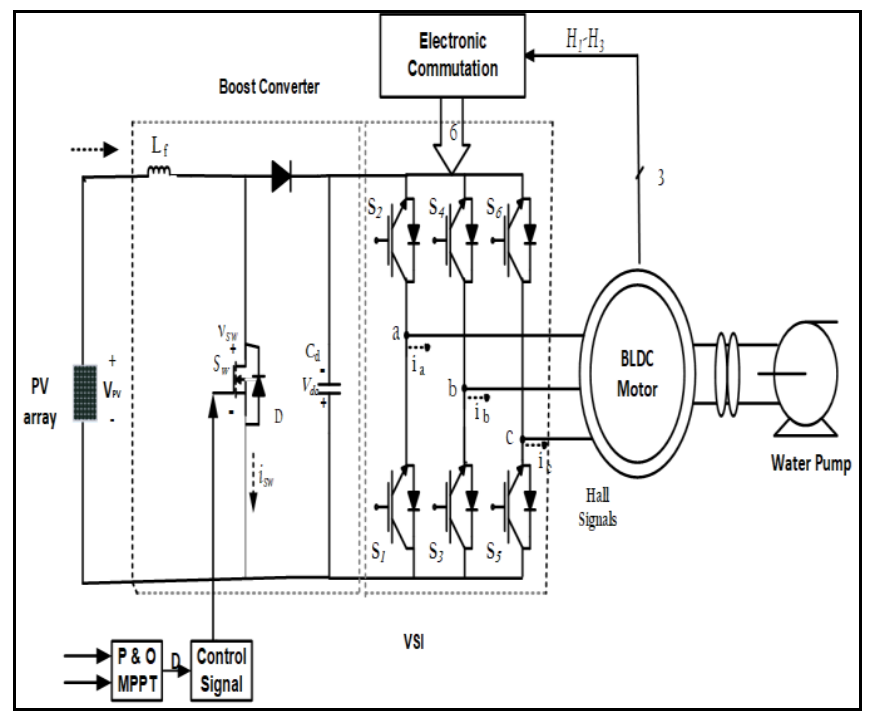

Fig-1 Configuration of the SPV array - boost converter fed BLDC motor driven water pump.

\section{DESIGN PARAMETERS}

The different working phases of the arrangement appeared in Fig.1, for example, the SPV cluster, the boost converter and the water pump are planned with the end goal that an acceptable activity is dependably achieved under any sort of variety in sun powered irradiance. The specialized determinations of a chose BLDC motor of $1.32 \mathrm{~kW}$ evaluated control are demonstrated in Table I. Alternate phases of the proposed framework are planned as needs be, as per the following.

\section{A. Design of Solar PV}

A sunlight based PV exhibit of $1.62 \mathrm{~kW}$ top power limit, to some degree more than required by the engine, is chosen with the goal that the execution of the framework isn't influenced by the misfortunes related with the converters and the engine. The parameters of the SPV cluster are evaluated at the standard sunlight based irradiance of $1000 \mathrm{~W} / \mathrm{m} 2$. A PV module HB-1290, fabricated by HBL Power System Ltd. [14] with top intensity of $90 \mathrm{~W}$ is considered to plan a SPV cluster of required limit. The voltage of the SPV exhibit at MPP is chosen in perspective of the DC voltage rating of the BLDC motor same as the DC interface voltage of the VSI. Table II abridges the estimation of the different parameters to outline a SPV exhibit of suitable size.

\begin{tabular}{|c|c|}
\hline \multicolumn{2}{|c|}{ For a PV Module } \\
\hline Numbers of cells in a module & 36 \\
\hline Open circuit voltage & $21 \mathrm{~V}$ \\
\hline Short circuit current & $6.4 \mathrm{~A}$ \\
\hline Voltage at MPP, Vm & $17 \mathrm{~V}$ \\
\hline Current at MPP, Im & $5.4 \mathrm{~A}$ \\
\hline For a PV & Array \\
\hline Voltage at MPP, $\mathrm{VmpR}=\mathrm{ypx}$ & $153 \mathrm{~V}$ \\
\hline Power at MPP, Pmpp $=p p v$ & $1620 \mathrm{~W}$ \\
\hline Current at MPP, Impp $=i p \mathrm{~V}$ & $\begin{array}{l}\text { Pmpp } / \text { Vmpp }=1620 / 153=10.6 \\
\text { A }\end{array}$ \\
\hline Numbers of modules in series, $\mathrm{Ns}$ & $\mathrm{Vmpp} / \mathrm{Vm}=153 / 17=9$ \\
\hline $\begin{array}{l}\text { Numbers of modules in parallel, } \\
\text { Na }\end{array}$ & $\mathrm{Impp} / \mathrm{Im}=10.6 / 5.4=1.963 \approx 2$ \\
\hline
\end{tabular}

B. Design of the Boost Converter

The SPV array voltage at MPP, vpv $=153 \mathrm{~V}$ shows up as the input voltage source though DC interface voltage of VSI, $\mathrm{vdc}=310 \mathrm{~V}$ shows up as the yield voltage of the boost converter.

The obligation proportion, $\mathrm{D}$ of boost converter is evaluated as [4, 13], where $\mathrm{Vdc}=310 \mathrm{~V}$ is a normal estimation of the DC interface voltage of the VSI.

$$
D=\frac{V d c-V p v}{V d c}=\frac{310-153}{310}=0.506
$$

Then again, dismissing the boost converter misfortunes, an normal current moving through the DC interface, Idc is approximated as,

$$
I_{d c}=\frac{P m m p}{V_{d c}}=\frac{1620}{310}=5.22 \mathrm{~A}
$$




\begin{tabular}{|c|c|c|c|c|}
\hline Parameter & Expression & Design data & Value & $\begin{array}{c}\text { Selected } \\
\text { value }\end{array}$ \\
\hline$L$ & $\begin{array}{c}\frac{D^{*} v_{p v}}{f_{w} \Delta I_{L}} \\
I_{L}=N_{p}^{*} I_{m}\end{array}$ & $\begin{array}{l}D=0.506 \\
v_{p v}=153 \mathrm{~V} \\
f_{s w}=20 \mathrm{kHz} \\
N_{p}=2 \\
I_{m}=5.4 \mathrm{~A} \\
\Delta I_{L}=6 \% \text { of } I_{L}\end{array}$ & $\begin{array}{l}5.97 \\
\mathrm{mH}\end{array}$ & $6 \mathrm{mH}$ \\
\hline C & $\begin{array}{l}\omega=2 * \pi^{*} f= \\
\frac{2^{*} \pi^{*} N_{t}^{*} P}{120} \\
{ }^{\prime} C=\frac{I_{d k}}{6 * \omega^{*} \Delta V_{d}}\end{array}$ & $\begin{array}{l}P=4 \\
N_{r}=3000 \mathrm{rpm} \\
V_{d k}=310 \mathrm{~V} \\
I_{d k}=5.22 \mathrm{~A} \\
\Delta V_{d k}=1 \% \text { of } V_{d k}\end{array}$ & $\begin{array}{c}446.6 \\
\mu \mathrm{F}\end{array}$ & $500 \mu \mathrm{F}$ \\
\hline
\end{tabular}

The SPV exhibit current, ipv moves through the inductor, $\mathrm{L}$. The plan of inductor, $\mathrm{L}$ and $\mathrm{DC}$ connect capacitor; $\mathrm{C}$ is outlined in Table III, where fsw is the exchanging recurrence of boost converter; IL is a normal current coursing through the inductor; $\Delta \mathrm{IL}$ is a measure of swell allowed in the current coursing through the inductor; $\Delta \mathrm{V}_{\mathrm{dc}}$ is the swell allowed in the voltage over the DC connection of VSI; $\omega$ and $\mathrm{f}$ are the VSI yield voltage frequencies in $\mathrm{rad} / \mathrm{sec}$. also, $\mathrm{Hz}$ individually; $\mathrm{P}$ is the quantity of posts in the BLDC motor and $\mathrm{Nr}$ is the evaluated speed of the engine. The estimations of converter parameters are chosen with the end goal that the execution of the proposed framework isn't decayed even under the lower sun oriented irradiance too.

\section{Design Of Water Pump}

A water pump, going about as a heap, is coupled to the shaft of BLDC motor. This pump is outlined by its capacity speed qualities as,

$$
K_{p}=\frac{P}{w_{r}^{3}}=\frac{1320}{\left(2 * \pi * \frac{3000}{60}\right)^{3}}=4.25 * 10^{-5} \mathrm{~W} /\left(\frac{\mathrm{rad}}{\mathrm{sec}}\right)^{3}
$$

where $\mathrm{Kp}$ is proportionality constant and $\omega \mathrm{r}$ is the appraised speed of chosen BLDC motor in $\mathrm{rad} / \mathrm{sec}$.

D. Switching states of VSI based on Hall effect signal states :

The switching is done in such a way that there is always a moving magnetic motive force and they should keep the rotor moving. The hall sensor is used to sense the position of the rotor and then send a signal on which the electronic computation occurs.

As per circuit switches $\mathrm{S} 1$ and $\mathrm{S} 2$ forms phase $\mathrm{A}, \mathrm{S} 3$ and S4 makes phase B and S5 and S6 make phase C. Positive sign represents that $\mathrm{S} 1$ or $\mathrm{S} 3$ or $\mathrm{S} 5$ is on respectively for each phase while negative sign shows that $\mathrm{S} 2$ or $\mathrm{S} 4$ or $\mathrm{S} 6$ is on respectively for each phase $\mathrm{ABC}$.

\begin{tabular}{|c|c|c|c|c|c|c|c|c|c|c|c|c|}
\hline \multirow{2}{*}{$\begin{array}{l}\text { Position } \\
\text { In degress }\end{array}$} & \multicolumn{3}{|c|}{ Hall signal } & \multicolumn{3}{|c|}{ Phases } & \multicolumn{6}{|c|}{ Switches } \\
\hline & $\mathrm{H}$ a & $\mathrm{Hb}$ & $\mathrm{H} c \mathrm{c}$ & A & B & $\mathrm{C}$ & S1 & S2 & S3 & $\$ 4$ & S5 & S6 \\
\hline $\mathrm{NA}$ & 0 & 0 & 0 & 0 & 0 & 0 & 0 & 0 & 0 & 0 & 0 & 0 \\
\hline $0-60$ & 1 & 0 & 1 & + & $\cdot$ & 0 & 1 & 0 & 0 & 1 & 0 & 0 \\
\hline $60-120$ & 1 & 0 & 0 & + & 0 & $\cdot$ & 1 & 0 & 0 & 0 & 0 & 1 \\
\hline $120-180$ & 1 & 1 & 0 & 0 & + & - & 0 & 0 & 1 & 0 & 0 & 1 \\
\hline $180-240$ & 0 & 1 & 0 & - & + & 0 & 0 & 1 & 1 & 0 & 0 & 0 \\
\hline $240-300$ & 0 & 1 & 1 & $\cdot$ & 0 & + & 0 & 1 & 0 & 0 & 1 & 0 \\
\hline $300-360$ & 0 & 0 & 1 & 0 & - & + & 0 & 0 & 0 & 1 & 1 & 0 \\
\hline $\mathrm{NA}$ & 1 & 1 & 1 & 0 & 0 & 0 & 0 & 0 & 0 & 0 & 0 & 0 \\
\hline
\end{tabular}

\section{E. Specification Of BLDC Motor}

\begin{tabular}{|l|l|}
\hline Power, $\mathrm{P}$ & $1.32 \mathrm{KW}$ \\
\hline Speed,N & $3000 \mathrm{rpm}$ \\
\hline DC voltage,Vdc & $310 \mathrm{~V}$ \\
\hline No of ploes,P & 4 \\
\hline Moment of inertia,J & $2.9 \mathrm{Kg} . \mathrm{cm} 2$ \\
\hline Current,I & $4.3 \mathrm{~A}$ \\
\hline Voltage constant,Ke & $78 \mathrm{Nm} / \mathrm{A}$ \\
\hline Torque constant,Kt & $0.74 \mathrm{Nm} / \mathrm{A}$ \\
\hline Phase/phase resistance, Rs & $3.58 \mathrm{Ohm}$ \\
\hline Phase/phase inductance,Ls & $9.13 \mathrm{mH}$ \\
\hline
\end{tabular}

\section{CONTROL OF PROPOSED SYSTEMS}

In the proposed system, SPV array is controlled through the INC-MPPT and VSI is controlled through the electronic commutation of BLDC motor, which are elaborated in the following sections.

\section{A. Maximum Power Point Tracking (MPPT)}

The MPPT technique is mostly used to optimize the efficiency in SPV based applications. P\&O type of MPPT method is used in this work because of its high precision of tracking even under the rapid change in the weather conditions. The perturbation size is selected as 0.001 such that the oscillation around the peak power point is avoided. The permissible starting current of the BLDC motor is ensured under all the possible variation in the solar irradiance by starting the tracking from initial duty ratio of zero.

\section{B. Electronic Commutation of BLDC Motor}

The switching signals for the VSI are generated through the electronic commutation of the BLDC motor. Following the rotor position, the Hall sensors provide three Hall-effect signals on $60^{\circ}$ span. These Hall-effect signals are logically converted into six switching pulses used to operate the VSI. Table-IV shows the switching states of VSI for each set of 3 Hall-effect signal states. The conduction of only two switches at a time results in a reduced conduction losses. 


\section{SIMULATION PERFORMANCE}

The performance of the proposed SPV powered BLDC motor-pump is simulated in MATLAB/Simulink environment using its Sim-power-system toolbox. The starting, dynamic and steady state performances are evaluated using the simulated results as discussed:

A. Irradiance And Temperature:

The Irradiance is given in three steps, ie, $500 \mathrm{~W} / \mathrm{m} 2$ for morning time $1000 \mathrm{~W} / \mathrm{m} 2$ for mid-day and $700 \mathrm{~W} / \mathrm{m} 2$ for evening. And temperature is fixed to 25 degree Celsius, as room temperature.

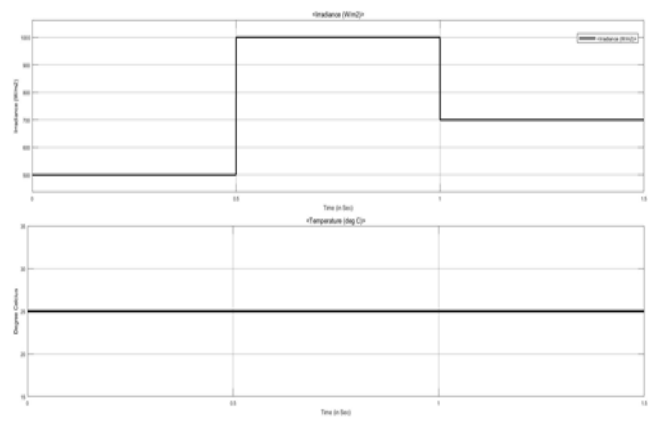

\section{B. Current, Voltage and Power from Spv}

The SPV array indices vpv, ipv, ppv and along with the solar irradiance, $S$ subjected to the rapid variation in solar irradiance from $200 \mathrm{~W} / \mathrm{m} 2$ to $1000 \mathrm{~W} / \mathrm{m} 2$. The SPV array, at MPP, changes its operating point from $212 \mathrm{~W}$ to $1620 \mathrm{~W}$.
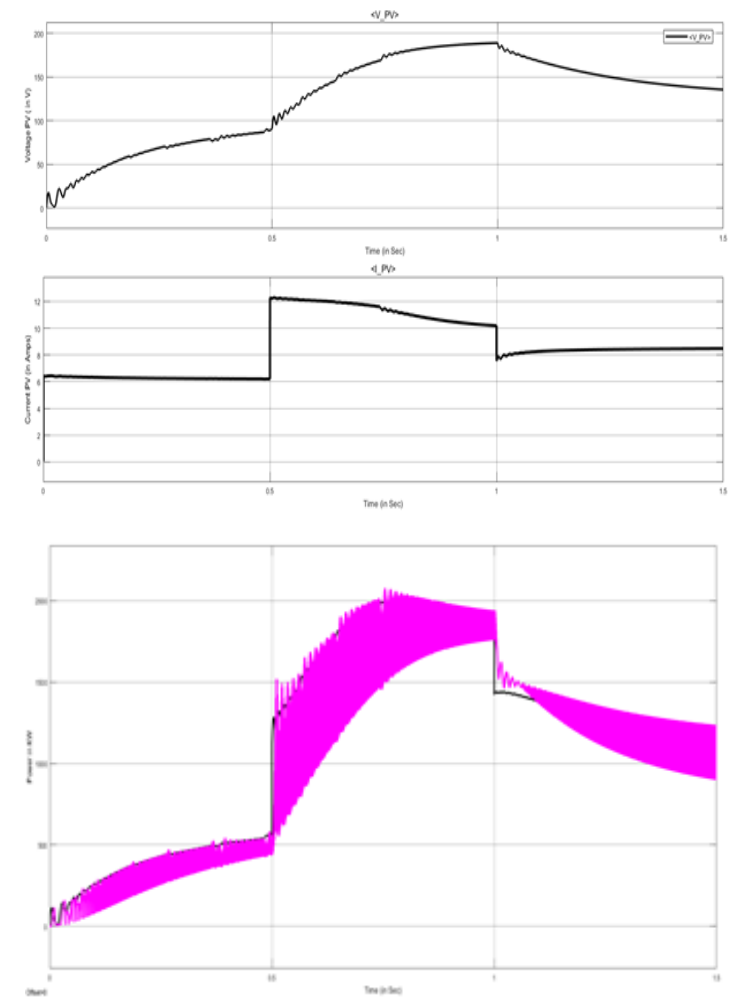

C. Current and Voltage from Boost Converter

The bellow figure indicates the dynamic behavior of boost converter. The inductor current, iL, DC link voltage, vdc, voltage stress on the switch, vSW, and current stress on the switch, iSW, are presented. It is observed from waveforms that the converter always operates in CCM irrespective of the variation in solar irradiance. The DC link voltage, vdc alters from $128 \mathrm{~V}$ to $310 \mathrm{~V}$ as the solar irradiance alters from 200 $\mathrm{W} / \mathrm{m} 2$ to $1000 \mathrm{~W} / \mathrm{m} 2$. Likewise, the other indices also follow the variation in solar irradiance.

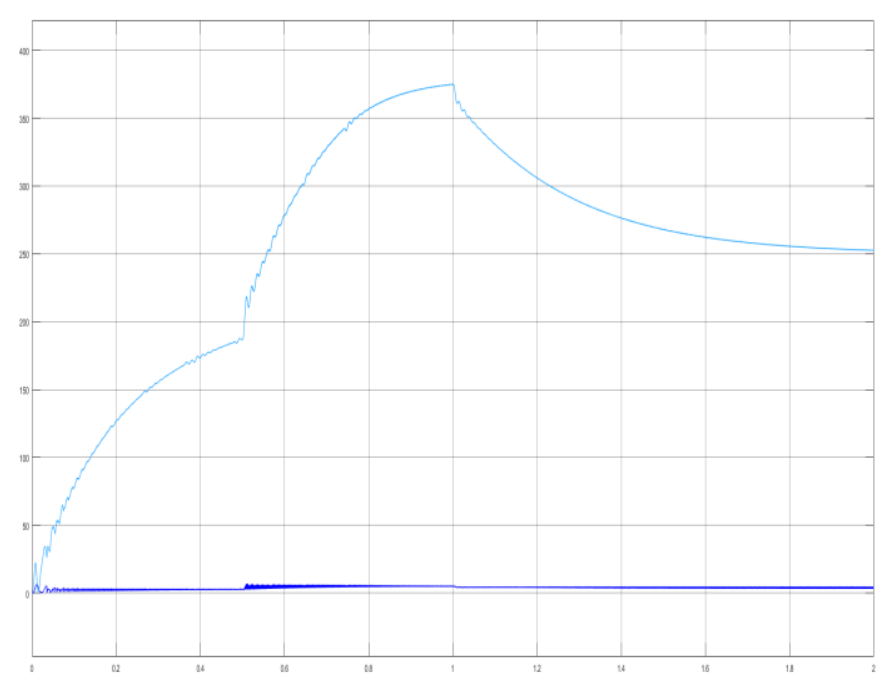

\section{Performance of BLDC Pump}

The bellow figure exhibits the dynamic behaviors of the BLDC motor-pump. The BLDC motor is started at the $20 \%$ of standard solar irradiance i.e. $200 \mathrm{~W} / \mathrm{m} 2$. The starting current of BLDC motor is bounded within the permissible range hence the motor has a soft start at $200 \mathrm{~W} / \mathrm{m} 2$ also. All the motor indices such as the back EMF, ea, the stator current, isa, the speed, $\mathrm{N}$, the electro-magnetic torque, Te and the load torque offered by pump, TL follow the variation in solar irradiance and reach their steady state values as MPP is tracked. The current drawn by the motor increases from $1.3 \mathrm{~A}$ to 4.3 A. Similarly, the speed increases from $1440 \mathrm{rpm}$ to $3000 \mathrm{rpm}$. The speed of $1440 \mathrm{rpm}$ is sufficient to pump the water, although not with the full capacity. This performance implies that the proposed water pumping system operates successfully even at the $20 \%$ of standard solar irradiance.,

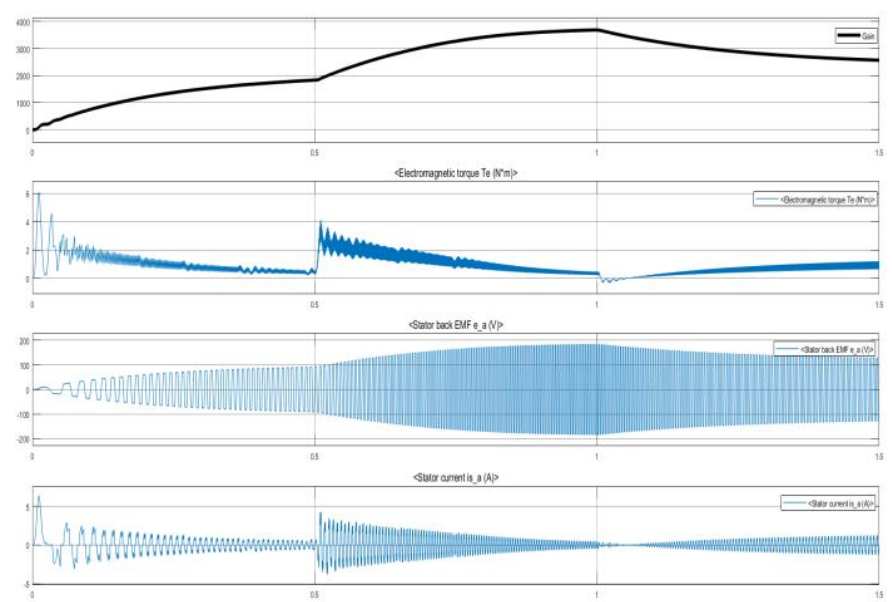




\section{RESULTS AND CONCLUSION}

A very good efficiency is obtained for the proposed water pumping system. Table $\mathrm{V}$ shows the efficiency estimation of the SPV array fed BLDC motor-pump, subjected to the variation in weather condition, where $\eta$ is efficiency of the overall system, excluding SPV array. Hence this efficiency estimation includes the efficiency of MPPT algorithm, boost converter, VSI and BLDC motor - pump. An efficiency of $79.7 \%$ is obtained at the minimum solar irradiance of 200 $\mathrm{W} / \mathrm{m} 2$. As the irradiance increases beyond $500 \mathrm{~W} / \mathrm{m} 2$, the efficiency of the system gets over $80 \%$

\begin{tabular}{|l|l|l|l|}
\hline \multicolumn{1}{|c|}{$\mathbf{S}(\mathbf{W} / \mathbf{m} 2)$} & \multicolumn{1}{|c|}{$\mathbf{P p v}(\mathbf{W})$} & \multicolumn{1}{c|}{$\boldsymbol{\eta}(\mathbf{\%})$} & 79.7 \\
\hline 200 & 212 & 169 & 79.8 \\
\hline 400 & 560 & 447 & 80.0 \\
\hline 500 & 741 & 593 & 80.2 \\
\hline 600 & 923 & 740 & 80.5 \\
\hline 800 & 1285 & 1034 & 80.6 \\
\hline 900 & 1466 & 1181 & 81.5 \\
\hline 1000 & 1620 & 1320 & \\
\hline
\end{tabular}

The sun oriented PV cluster based BLDC motor driven water pumping framework utilizing a DC-DC help converter has been proposed and its appropriateness has been confirmed by execution assessments under the reasonable working conditions. The reconciliation of boost converter and BLDC motor into the SPV exhibit for water pumping has been risen as a doable arrangement in setting of straightforwardness, sparing, minimization, effectiveness, unwavering quality and accessibility. The execution examination has shown the guaranteed novel highlights of proposed framework, for example, MPPT with help converter by appropriate plan of SPV exhibit; speed control of BLDC motor by factor DC connect voltage and delicate beginning of

The engine by shrewdly following the MPP, both with no control circuits and detecting components; and electronic substitution with key recurrence exchanging. Other than these, fruitful activity even at $20 \%$ of sunlight based irradiance has uncovered that the proposed framework is without a doubt worthy for water pumping.

\section{REFERENCES}

[1] S. Jain, A.K. Thopukara, R. Karampuri and V.T. Somasekhar, "A Single-Stage Photovoltaic System for a Dual-Inverter-Fed Open-End Winding Induction Motor Drive for Pumping Applications," IEEE Transactions on Power Electronics, vol. 30, no. 9, pp. 4809 - 4818 , Sept. 2015

[2] Le An and D.D.-C. Lu, "Design of a Single-Switch DC/DC Converter for a PV-Battery-Powered Pump System With PFM+PWM Control," IEEE Transactions on Industrial Electronics, vol. 62, no. 2, pp. 910 - 921, Feb. 2015.

[3] J.V. Mapurunga Caracas, G. De Carvalho Farias, L.F. Moreira Teixeira and L.A. De Souza Ribeiro, "Implementation of a HighEfficiency, High-Lifetime, and Low-Cost Converter for an Autonomous Photovoltaic Water Pumping System," IEEE Transactions on Industry Applications, vol. 50, no. 1, pp. 631-641, Jan.-Feb. 2014

[4] M. H. Rashid, Power Electronics Handbook: Devices, Circuits, and Applications," $3^{\text {rd }}$ ed. Oxford, UK: Elsevier Inc., 2011

[5] M. Ouada, M.S. Meridjet and N. Talbi, "Optimization Photovoltaic Pumping System Based BLDC Using Fuzzy Logic MPPT Control," International Renewable and Sustainable Energy Conference (IRSEC), pp.27-31, 7-9 March 2013.

[6] B. Singh and V. Bist, "A BL-CSC Converter-Fed BLDC Motor Drive With Power Factor Correction," IEEE Transactions on Industrial Electronics, vol. 62, no. 1, pp. 172-183, Jan. 2015.

[7] Rajan Kumar and Bhim Singh, "Buck-boost converter fed BLDC motor drive for solar PV array based water pumping," IEEE International Conference on Power Electronics, Drives and Energy Systems (PEDES), 16-19 Dec. 2014, pp. 1-6.

[8] R. Parackal and R.A. Koshy, "PV powered zeta converter fed BLDC drive," Annual International Conference on Emerging Research Areas: Magnetics, Machines and Drives (AICERA/iCMMD), 24-26 July 2014, pp.1-5.

[9] S.A.KH. Mozaffari Niapour, S. Danyali, M.B.B. Sharifian and M.R Feyzi, "Brushless DC Motor Drives Supplied by PV Power System Based on Z-Source Inverter and FL-IC MPPT Controller," Energy Conversion and Management, vol. 52, no. 8-9, pp. 3043-3059, August 2011 